\title{
Estimativa de vazão da água condensada proveniente de aparelhos condicionadores
}

\author{
de ar \\ Estimated flow of condensed water from air conditioners \\ Flujo estimado de agua condensada de acondicionadores de aire
}

Recebido: 26/09/2021 | Revisado: 03/10/2021 | Aceito: 04/10/2021 | Publicado: 05/10/2021

Davi Souza Marinho

ORCID: https://orcid.org/0000-0003-3323-2660 Universidade Federal da Paraíba, Brasil E-mail: Davimarinhodsm@gmail.com

Gilson Barbosa Athayde Júnior

ORCID: https://orcid.org/0000-0003-2815-7600 Universidade Federal da Paraíba, Brasil

E-mail: gilson.athayde@academico.ufpb.b

Igor do Nascimento Quaresma

ORCID: https://orcid.org/0000-0002-9119-1011

Universidade Federal da Paraíba, Brasil

E-mail: igor_nq@hotmail.com

\begin{abstract}
Resumo
O aumento populacional, responsável pela crescente demanda por água potável, atrelada à poluição e ao uso nãoracional da água, resulta em um cenário de escassez hídrica em determinadas regiões de todos os continentes, principalmente nas regiões de baixa precipitação. Buscando reduzir o consumo de água potável para fins menos nobres, diminuir a pressão sob os reservatórios hídricos e combater a escassez hídrica, surge o conceito de uso racional da água. Baseado nos princípios da minimização, separação e reutilização, tal conceito traz consigo a sugestão do uso de fontes alternativas de água, sendo uma delas a água condensada proveniente do funcionamento de aparelhos condicionadores de ar. Tais aparelhos funciona de forma que ocorre a condensação de água, sendo este efluente, em sua grande maioria, desprezado. O presente trabalho objetiva delinear modelos para estimativa da vazão de água gerada pela condensação em aparelhos de ar condicionado. Foram realizadas coletas do volume gerado pelos aparelhos e análise quantitativa da vazão da água compensada. Com os resultados, foi possível delinear um modelo matemático para estimação da vazão desta fonte alternativa de água, que possibilita a análise da viabilidade do seu uso em determinado local para fins não potáveis, como a lavagem do piso, descargas em bacias sanitárias e irrigação.
\end{abstract}

Palavras-chave: Escassez hídrica; Reuso de água; Água de condensação.

\begin{abstract}
Population growth, responsible for the growing demand for drinking water, related to pollution and non-rational use of water, results in a scenario of water scarcity in certain regions of all continents, especially in regions of low rainfall. Seeking to reduce the consumption of drinking water for less noble purposes, reduce pressure under water reservoirs and combat water scarcity, the concept of rational use of water emerges. Based on the principles of minimization, separation and reuse, this concept brings with it the suggestion of the use of alternative sources of water, among of them the condensed water from the operation of air conditioners. Such devices work in a way that water condensation occurs, and this effluent is mostly despised. The present work aims to delineate models to estimate the flow of water generated by condensation in air conditioners. The volume of condensed water generated by the devices was measured. Results allowed delineating a mathematical model to determine the flow of this alternative water source, which allows the analysis of the feasibility of its use in a given location for non-potable purposes, such as floor washing, discharges in sanitary basins and irrigation.
\end{abstract}

Keywords: Water scarcity; Water reuse; Condensed water.

\section{Resumen}

El aumento poblacional responsable de la creciente demanda de agua potable, ligada a la contaminación y al uso no racional del agua, da como resultado un escenario en el que la escasez de agua está presente a nivel mundial, especialmente en regiones con clima seco y / o escasas precipitaciones. Buscando reducir el consumo de agua potable para fines menos nobles, reducir la presión sobre los depósitos de agua y combatir la escasez de agua, surge el concepto de uso racional del agua. Sobre la base de los principios de minimización, separación y reutilización, este concepto trae consigo la sugerencia de utilizar fuentes alternativas de agua, una de las cuales es el agua proveniente del funcionamiento de los acondicionadores de aire. Los acondicionadores de aire funcionan de tal manera que se produce 
la condensación del agua y este efluente, en su mayor parte, se desecha. El presente trabajo fue creado con el objetivo de delinear modelo matemático para estimar el caudal de agua generado por la condensación en aires acondicionados. Se realizaron recolecciones del volumen generado por los dispositivos y análisis cuantitativo del caudal de agua compensada. Con los resultados, fue posible delinear un modelo matemático para estimar el caudal de esta fuente alternativa de agua, que permite analizar la factibilidad de su uso en un lugar determinado para fines no potables, como lavar el piso, descargar inodoros. y riego.

Palabras clave: Escasez de agua; Reutilización del agua; Agua de condensación.

\section{Introdução}

No Brasil, a Política Nacional de Recursos Hídricos, Lei Federal 9.433 de 1997, estabelece como um de seus objetivos assegurar a disponibilidade hídrica, nos padrões apropriados, para as atuais e futuras gerações (Brasil, 1997). Paralelamente, a Lei Federal $n^{\circ} 11.445$ de 2007, que estabelece diretrizes nacionais para o saneamento básico, tem entre seus princípios fundamentais, o acesso universal da população ao abastecimento de água, esgotamento sanitário, limpeza urbana e manejo dos resíduos sólidos realizados de formas adequadas à saúde pública e à proteção do meio ambiente (Brasil, 2007).

A água é uma substância de extrema importância para o funcionamento da vida na Terra, sendo sua distribuição 97,5\% em água salgada e 2,5\% água doce. Da parcela de água doce, apenas 0,3\% está em corpos hídricos (lagos e rios); 0,7\% em reservatórios subterrâneos não muito profundos; $30 \%$ em águas subterrâneas e a maior parcela, 69\%, se encontra em geleiras e neves eternas (Reichardt, 2016). O autor ainda destaca que a poluição dos corpos hídricos, também afeta a oferta de água, visto que abaixa a qualidade dos corpos hídricos, acarretando a necessidade de tratamentos mais sofisticados para o consumo humano. Sendo assim, além de prejudicar o meio ambiente como um todo, a poluição também gera um aumento nos custos de tratamento e abastecimento de água.

Atualmente, a população mundial cresce em média 0,9\% ao ano, e alcançará 9,7 bilhões de pessoas em 2050 (Iea,2018). Tal crescimento resulta no aumento da demanda dos recursos hídricos, que por serem finitos, podem gerar uma crise de abastecimento em escala global, impondo um racionamento de água permanente à sociedade. De acordo com Tayara et al. (2021), a urbanização e o crescimento populacional provocaram uma exploração desenfreada, além da contaminação dos recursos de água doce de todo o planeta, resultando em uma forte pressão pela demanda de água nas regiões áridas e semiáridas.

Neste sentido, Mekonnen e Hoekstra (2016) destacam que o aumento constante da demanda por água resulta na escassez de água doce, sendo uma ameaça ao desenvolvimento sustentável. Os autores supracitados estimam que dois terços da população mundial vivem em condições de grande escassez de água, por um período de pelo menos um mês por ano (Mekonnen; Hoekstra, 2016). Tal problemática pode ainda ser afetada pela poluição dos corpos hídricos, acarretando na piora da qualidade da água doce disponível no mundo (Ercin; Hoekstra, 2014).

Assim, os principais fatores que poderão afetar a disponibilidade de recursos hídricos são o crescimento populacional, crescimento econômico, alteração dos padrões de produção e consumo e o aumento da demanda por água, tanto para fins domésticos, como industriais e agrícolas (Ercin; Hoekstra, 2014).

Para mudar esse cenário faz-se necessário o uso de políticas sustentáveis e de medidas que fomentem o uso racional da água. Em 2010 foi sancionada a Lei Estadual № 9.130, que estabelece o Programa de Conservação e Uso Racional da Água nas Edificações Públicas da Paraíba, retratando, no Art. $2^{\circ}$, a importância do uso racional, do reaproveitamento e da utilização de fontes alternativas para a captação de água, assim como fomentar a conscientização dos usuários (Paraíba, 2010). No ano de 2015 foi promulgada a Lei Estadual da Paraíba № 10.559, que estimula práticas de uso racional da água e instiga o uso de fontes alternativas, como por exemplo o reuso de águas, visto a escassez hídrica ocorrida no decorrer dos últimos anos no estado (Paraíba, 2015).

Uma das formas bastante eficaz de amortizar a pressão sobre os mananciais, responsáveis por abastecer a demanda hídrica gerada, é o uso de fontes alternativas de água, como por exemplo a reutilização de águas residuais, que se apresenta como 
uma abordagem eficaz para solucionar a escassez de recursos hídricos (Ren; Zhang; Chen, 2020). Neste sentido, a água proveniente da condensação em aparelhos condicionadores de ar se destaca pelo alto potencial de aproveitamento, podendo ser utilizada para lavagem de pisos e regas de plantasse até outros usos mais nobres (Sousa et al.,2016). Segundo Nenganga (2014) a quantidade de água produzida pelo aparelho de ar-condicionado depende da marca, potência e condições climáticas.

Neste contexto, Arden et al. (2021) desenvolveram um modelo para avaliar a viabilidade ambiental e econômica de tecnologias para a reutilização de água para fins não potáveis, como a água condensada oriunda de aparelhos de ar-condicionado. Este modelo foi projetado para analisar a implantação destas tecnologias em edifícios localizados nos Estados Unidos. Como resultado Arden et al. (2021) afirmam que os sistemas de aproveitamento de água condensada por aparelhos de ar-condicionado têm potencial para satisfazer até $26 \%$ da demanda de água dos edifícios norte-americanos. Segundo os autores, a disponibilidade de água para o sistema dependerá do clima local e de algumas características do edifício.

Em pesquisa realizada em um órgão de administração pública na Paraíba, Rodrigues et al. (2019) quantificaram o volume de água condensada de 57 aparelhos de ar-condicionado, com potências de 7.000 BTU, 10.000 BTU, 12.000 BTU, 16.000 BTU, 18.000 BTU e 30.000 BTU. Além disso, os autores realizaram análises físico-química e microbiológica para atestar a boa qualidade da água. Como resultado, foi estimado um volume total de água condensada de 11,69 m³/mês, ou 140 mªno. A média o consumo mensal do órgão público analisado foi de $157 \mathrm{~m} / \mathrm{mês}$. Desta forma, a vazão de água condensada gerada pelos aparelhos de ar-condicionado representa 7,5\% do consumo total do órgão. Assim, o aproveitamento desta água pode gerar uma redução de 7,5\% do consumo de água oriunda da concessionária (Rodrigues et al., 2019). Os autores ainda completam que as análises físico-química e microbiológica atestaram qualidade satisfatória da água condensada, quando comparadas aos padrões estabelecidos para as classes de água de reuso I e III, podendo ser utilizada para o uso em descargas de bacias sanitárias, lavagem de pisos, fins ornamentas, lavagem de roupa e veículos; e para fins de irrigação de áreas verdes e rega de jardins (Ana, 2005).

Em pesquisa cujo objetivo foi analisar o potencial de aproveitamento fontes alternativas de água, como as oriundas de sistemas de ar-condicionado do Departamento de Engenharia Agronômica (DEA) da Universidade Federal de Viçosa, Da Silva et al. (2019) estimaram a quantidade de água condensada coletada por 46 aparelhos de ar-condicionado. Como resultado, os autores estimaram uma produção de água condensada em 2,31 m³/mês, correspondendo a 1,34\% da demanda de água na instituição (Da Silva et al., 2019).

Siam et al. (2019) analisaram o potencial de aproveitamento de água condensada por aparelhos de ar-condicionado nas cidades palestinas de Ramallah e Jericho (Cisjordânia). Para tanto, os autores coletaram um total de 65 amostras de água condensada, sendo 32 em Ramalhah e 33 em Jericó. As amostras foram coletadas de diferentes tipos de construções, como supermercados, restaurantes, farmácias, padarias, residências e edifícios de escritórios. Os autores também investigaram a qualidade da água condensada, analisando parâmetros físicos, químicos e biológicos (Siam et al., 2019).

$\mathrm{Na}$ cidade de Ramallah, o volume de água gerado foi analisado para temperaturas de $16^{\circ} \mathrm{C}$ e $18^{\circ} \mathrm{C} \mathrm{em}$ aparelhos com potências de 12000, 24000 e 36000 Btu. Como resultado Siam et al. (2019) estimam que para temperaturas de $16^{\circ} \mathrm{C}$, a vazão de água condensada foi de 1,45, 2,78 e 3,78 1/h, para aparelhos de ar-condicionado de 12000, 24000 e $36000 \mathrm{Btu}$, respectivamente. Já para temperaturas de $18^{\circ} \mathrm{C}$, as vazões de água condensada foram de 1,30, 2,26 e 3,17 1//h para aparelhos de ar-condicionado de 12000, 24000 e 36000 Btu. respectivamente (Siam et al., 2019).

Para a cidade de Jericó, o volume de água condensada foi analisado para temperaturas de $18^{\mathrm{a}} \mathrm{C}$ e $20^{\mathrm{a}} \mathrm{C}$. Para a primeira temperatura, os autores estimam que a geração e água condensada é de 1,02, 2,39 e 2,87 1/h, para aparelhos de ar-condicionado de 12000, 24000 e 36000 Btu., respectivamente (Siam et al., 2019). Já para $20^{\mathrm{a}} \mathrm{C}$, estes valores diminuem para 0,98, 2,10 e 2,72 1/h. Siam et al. (2019) validaram a qualidade da água de condensação através de analises físicas, químicas e microbianas, mostrando que esta água tem uma boa qualidade, estando em conformidade com os padrões palestinos para água de irrigação reutilizada. 
Bastos, Túlio e Franci, 2015, analisaram a redução do consumo de água potável através do aproveitamento da água condensada por aparelhos de ar-condicionado. O estudo ocorreu em uma clínica odontológica de $2500 \mathrm{~m}^{2}$ de área. Na clínica existiam 15 aparelhos de ar-condicionado com potencias variando entre 9000 e 60000`Btu.

Como resultado, os autores apontam que o sistema de refrigeração da clínica é capaz de gerar 330 litros/dia de água condensada, sendo 117 litros/dia a demanda de água da clínica para sua limpeza e manutenção. Dessa forma, 100\% dessa demanda seria atendida com água condensada, restando ainda 213 lítros/dia. A demanda de água destinada para bacias sanitárias é de 941 litros/dia, dessa forma o volume de água condensada restante das atividades de manutenção poderia atender 23\% desta demanda (Bastos; Túlio; Franci, 2015).

Diante do exposto, o objetivo deste artigo foi delinear modelos matemáticos para a estimativa da vazão de água proveniente da condensação em aparelhos de ar condicionado.

\section{Metodologia}

O trabalho se deu por meio da realização de consultas documentais e bibliográficas pertinentes ao tema, pesquisas de campo, coletas de dados e informações relevantes ao estudo e análise estatística dos dados coletados. Assim, a abordagem desta pesquisa foi predominantemente quantitativa, uma vez que buscou-se encontrar um modelo equacional que estime a vazão de água gerada pela condensação em aparelhos condicionadores de ar, por meio de parâmetros que exerçam influência nessa vazão. Desta forma, esta pesquisa se caracteriza por ser quantitativa (Richardson, 2017) e explorativa-descritiva (Gil, 2007).

\subsection{Descrição climatológica da região de estudo}

A região onde realizou-se o estudo foi na cidade de João Pessoa, Paraíba. Localizada no litoral do Nordeste, o município se enquadra, de acordo com a classificação climática de Köppen-Geige, como tipo “Am”, que define um clima tropical úmido, caracterizado por apresentar a temperatura média do mês mais frio, sempre superior a $18^{\circ} \mathrm{C}$, apresentando uma estação seca de pequena duração que é compensada pela elevada precipitação total acumulada (Embrapa,2018).

A cidade de João Pessoa apresenta temperaturas predominantemente elevadas, comparadas as temperaturas médias de outros locais do país, tendo as temperaturas mais baixas concentradas entre meses de junho e setembro e as temperaturas mais elevadas concentradas nos meses de dezembro a abril. Outra característica térmica marcante é a baixa variabilidade térmica (Inmet, 2018). Joao Pessoa também pode ser caracterizada por apresentar teores de umidade relativa do ar variando entre $72 \%$, no mês de outubro e 81,9\% em junho, de modo que a umidade relativa anual média é de 75,9\% (INMET,2010). A Figura 1 ilustra a umidade relativa do ar da cidade de João Pessoa durante o ano. 
Figura 1 - Umidade relativa do ar da cidade de João Pessoa/Pb.

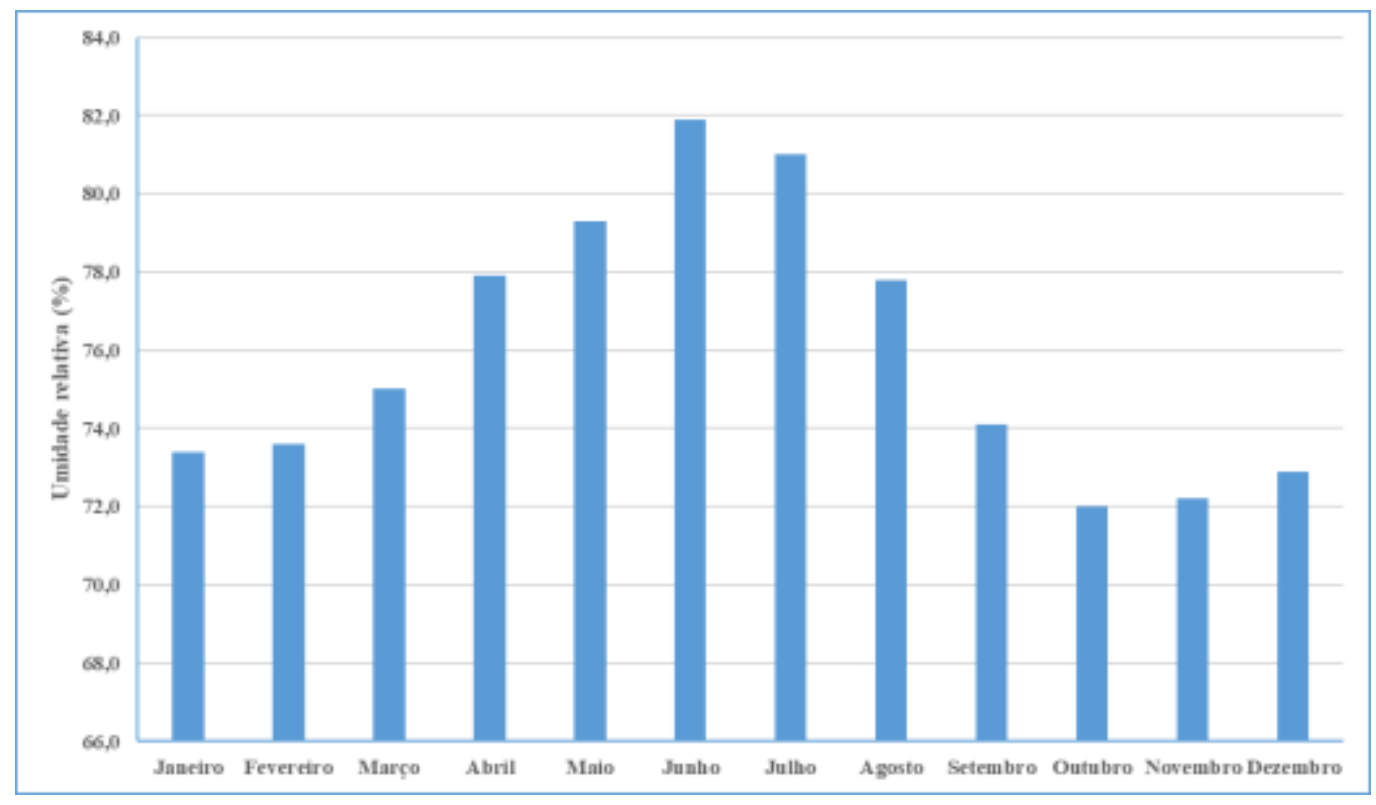

Fonte: Inmet (2010).

\subsection{Parâmetros estudados}

Para o presente estudo, buscou-se analisar parâmetros que influenciassem na vazão da água proveniente da condensação em aparelhos condicionadores de ar. Outra característica desejada era que esses fatores fossem informações mais abrangentes, que se apresentassem de forma mais acessível na etapa de estudo de viabilidade, menos sujeitos a variações devido a características específicas do local, no qual o sistema de aproveitamento será implantado. Os parâmetros escolhidos para o estudo foram a umidade relativa do ar e a potência dos aparelhos.

A umidade do ar, resumidamente, representa a quantidade de vapor de água contido na atmosfera, já a umidade relativa do ar é a relação entre a quantidade de água existente no ar e a quantidade máxima que poderia haver na mesma temperatura. Ela é um dos indicadores usados na meteorologia para se saber como o tempo se comportará, pois, ao subirem para a atmosfera, as gotículas de água se concentram, formando nuvens, que ao se resfriar, a água contida se precipita, em forma de chuva (INMET, 2018). Então, considerou-se que esse fator teria influência considerável na vazão da água condensada pelo funcionamento dos aparelhos de ar condicionado, pois afeta diretamente a quantidade de água presente no ar que passará pelo processo de resfriamento nos aparelhos.

Assim, foram escolhidos aparelhos condicionadores de ar a serem estudados e realizaram-se várias coletas da água condensada, proveniente do funcionamento desses equipamentos, com o intuito de quantificar sua vazão e buscar relações com os parâmetros citados anteriormente.

\subsection{Locais de coleta}

Foram coletadas amostras para medição de vazões das águas provenientes da condensação em aparelhos de ar condicionado em diversos locais da cidade de João Pessoa. Os ambientes apresentavam características diferentes entre si, foram estudados aparelhos condicionadores de ar utilizados em: escolas, estabelecimentos comerciais, residências, postos de gasolina, e universidades.

\subsection{Materiais utilizados}

Os materiais escolhidos para realizar as coletas de vazão foram as garrafas PET, como mostra a Figura 2. Além de 
poderem se acoplar facilmente às tubulações responsáveis pela drenagem dos condicionadores de ar, também se adaptam às peculiaridades do acesso aos drenos dos equipamentos em cada local de coleta, devido aos diferentes tamanhos e formas em que as garrafas PET podem ser encontradas, sendo possível, ainda, a vedação com tampa para serem transportadas até o medidor de volume, após a realização da coleta. O instrumento utilizado para a medição dos volumes coletados foi uma proveta graduada de $1000 \mathrm{ml}$ com base sextavada, com precisão de $\pm 10 \mathrm{ml}$.

Figura 2 - Garrafa PET utilizada na coleta de dados.

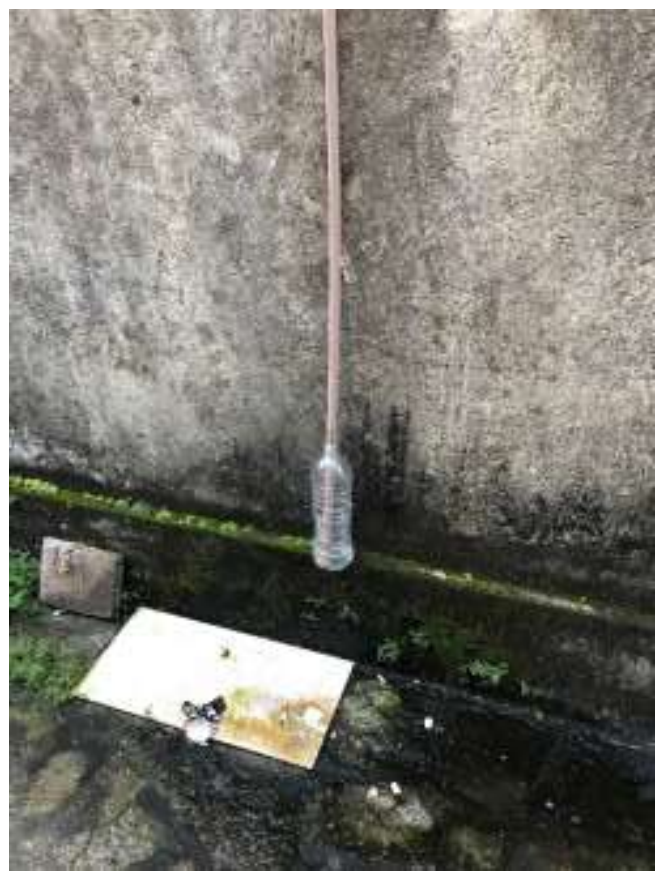

Fonte: Autores (2021).

Para realização dos estudos de campo, foram desenvolvidas fichas de coleta onde foram inseridas todas as informações pertinentes ao trabalho, como por exemplo, a potência do aparelho em BTU/h, a umidade relativa do ar da hora correspondente, o tempo de coleta, o volume coletado e a vazão em horária. Todas as coletas foram feitas sem a presença de chuva, de modo a não alterar o volume coletado e não exercer influência na análise quantitativa da vazão. Buscou-se fazer cada coleta por um tempo mínimo em torno de 30 minutos, para cobrir possíveis oscilações de vazões em decorrência do funcionamento dos aparelhos condicionadores de ar.

\subsection{Tratamento estatístico e análise dos dados coletados}

Foi realizada uma análise de regressão linear de múltiplas variáveis por meio do software IBM SPSS STATISTICS (Trial Version), na qual a vazão foi escolhida como variável dependente e as variáveis independentes foram a umidade relativa do ar e a potência dos aparelhos em BTU/h. Por meio desse processo obteve-se um modelo equacional que possibilita estimar a vazão da água condensada em condicionadores de ar, por meio da umidade relativa do ar e a potência em BTU/h do aparelho.

\section{Resultados e Discussão}

Foram estudadas as vazões da água condensada em 13 condicionadores de ar distintos. Para relacionar a vazão com a umidade do ar e analisar de que maneira ela é influenciada por esse fator, foram separadas as vazões de um mesmo aparelho condicionador de ar, colhidas em momentos com diferentes níveis de umidade relativa do ar. Assim, foram escolhidos somente 
os aparelhos com dados suficientes para essa análise, com pelo menos 3 valores de umidades distintos entre si. A figura 3 ilustra o gráfico vazão x umidade de um ar-condicionado localizado em um posto de combustível, cujo tempo de funcionamento diário é de 10 horas.

Figura 3 - Vazão x Umidade (Coleta 02 - 24000 BTU/h).

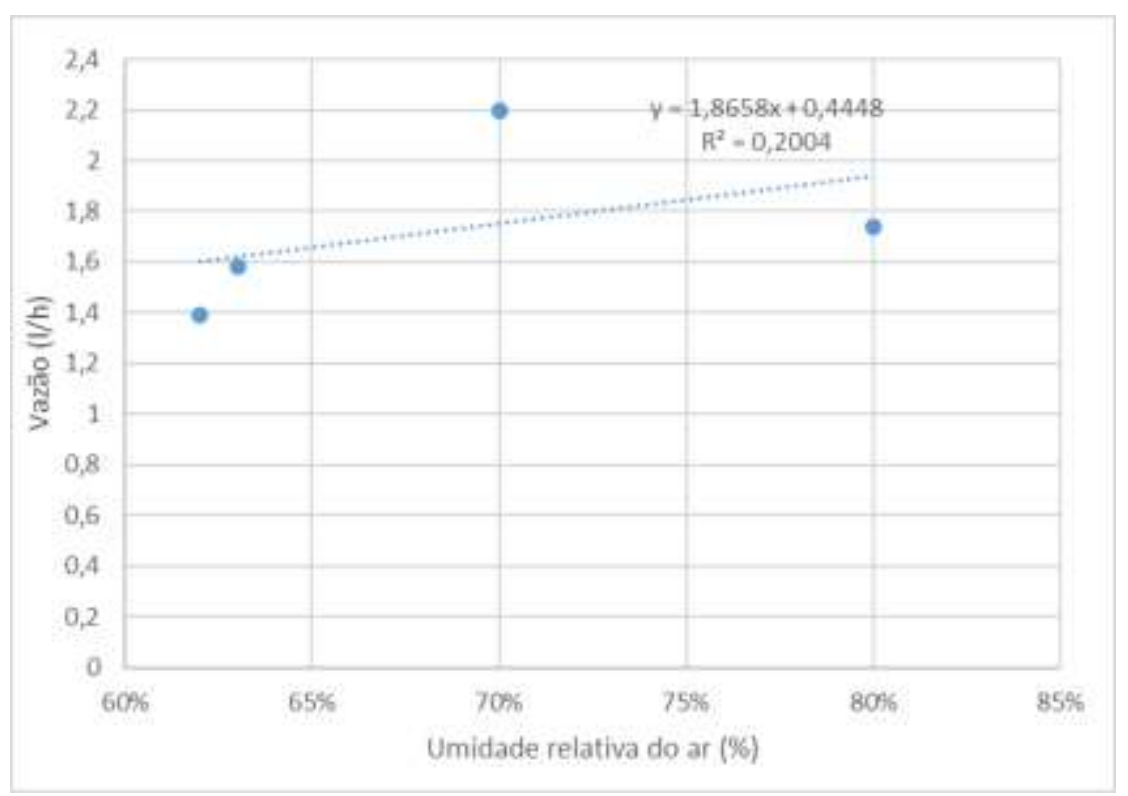

Fonte: Autores (2021).

A potência deste aparelho é de 24000 BTU/hora. Para este aparelho foram realizadas seis coletas, com o volume medido variando entre 0,241 e 0,99 , já a vazão variou entre 0,96 1/h e 2,2 1/h, com a umidade variando entre $62 \%$ e $80 \%$.

A Figura 4 ilustra o gráfico vazão x umidade de um ar-condicionado com potência de 18000 BTU/h, e que também é localizado em um posto de combustível, cujo uso diário é de 10 horas. Para este aparelho foram realizadas sete medições, cujo volume coletado variou entre 0,551 e 0,781 . A vazão medida variou entre 1,01 1/h e 1,54 1/h. Para este cenário, a umidade variou entre $62 \%$ e $80 \%$ 
Research, Society and Development, v. 10, n. 13, e104101321100, 2021

(CC BY 4.0) | ISSN 2525-3409 | DOI: http://dx.doi.org/10.33448/rsd-v10i13.21100

Figura 4 - Vazão x Umidade (Coleta 03 - 18000 BTU/h).

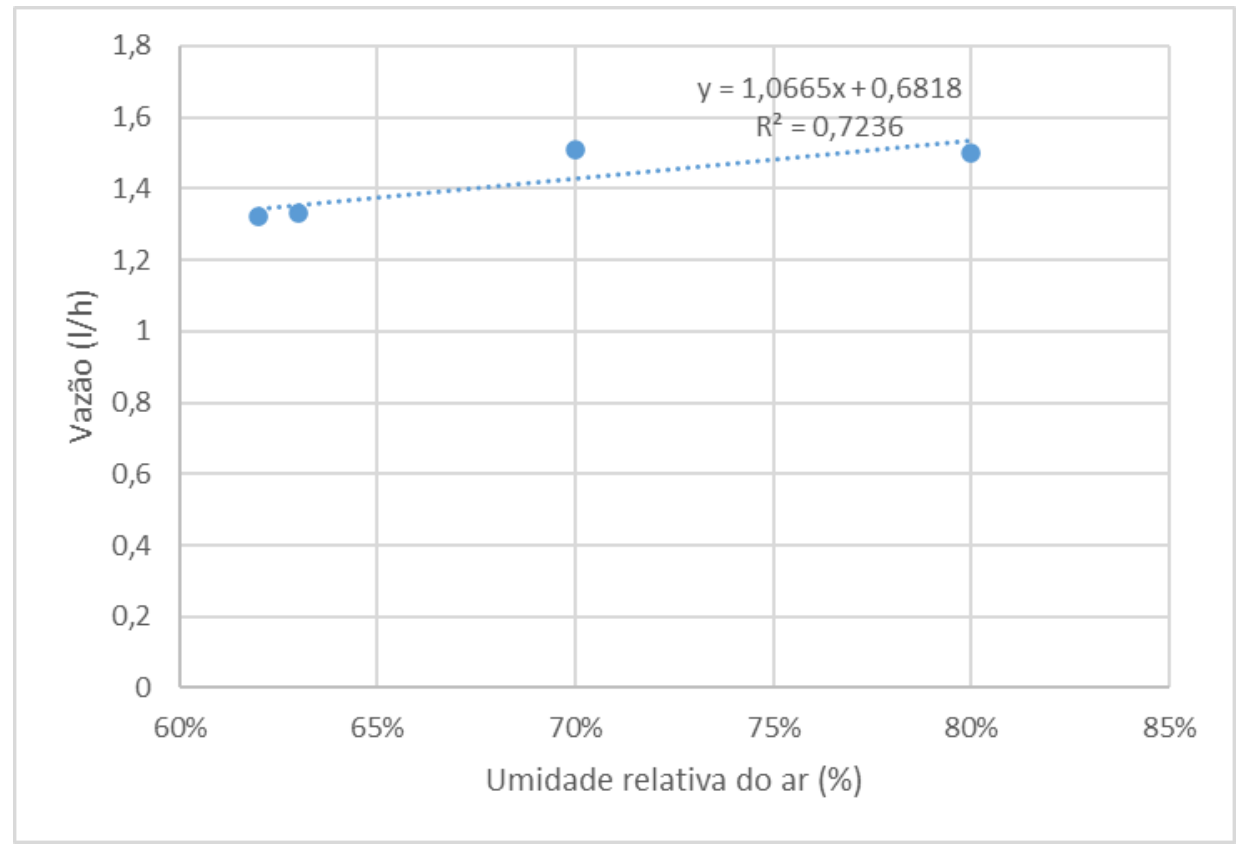

Fonte: Autores (2021).

A Figura 5 ilustra o gráfico vazão x umidade de um aparelho de ar-condicionado com uma potência de 9000 BTU/h. Este aparelho também é localizado em um posto de combustível, cujo período de utilização é de 10 horas por dia. Neste cenário foram realizadas três medições, com o volume coletado variando entre 0,361 e 0,531 , e a vazão entre 0,60 l/h e 0,74 l/h. A umidade variou entre $62 \%$ e $70 \%$

Figura 5 - Vazão x Umidade (Coleta 05 - 18000 BTU/h).

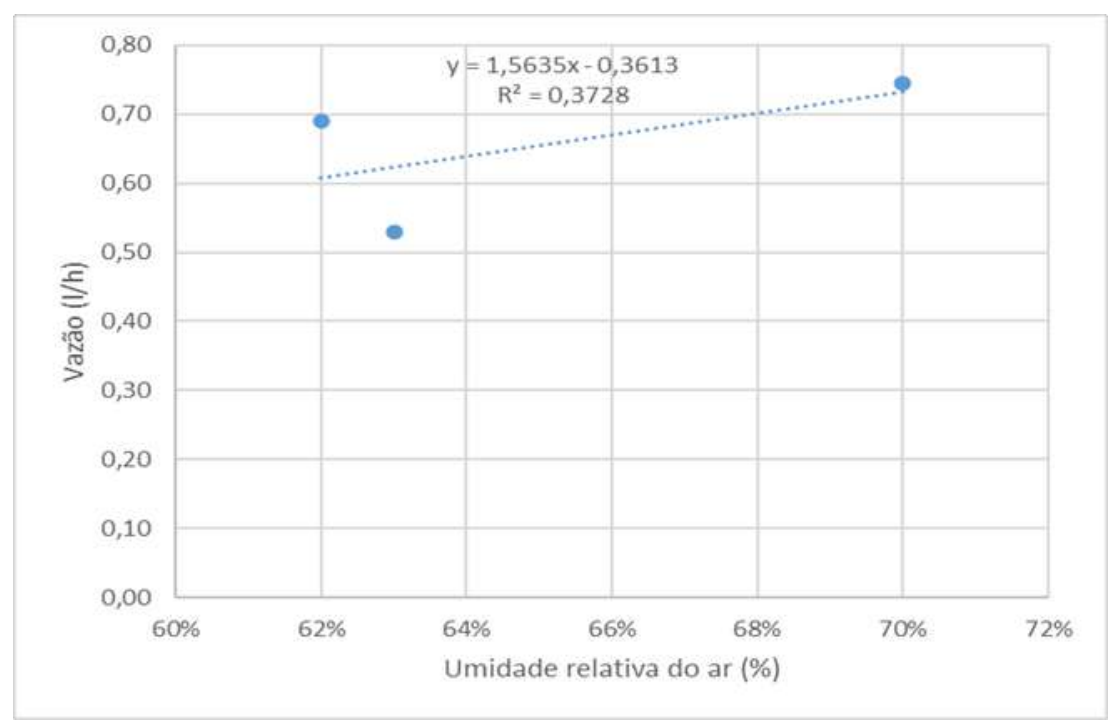

Fonte: Autores (2021).

A Figura 6 representa o gráfico da relação vazão x umidade para um aparelho de ar-condicionado com uma potência de 9000 BTU/h e localizado em uma residência unifamiliar, tendo um uso diário de oito horas. Neste aparelho foram realizadas quatro medições, com a umidade variando entre $61 \%$ e $79 \%$, volume entre 0,51 1 e 1,60 1, e vazão variando entre 1,02 1/h e 1,28 $1 / \mathrm{h}$. 
Figura 6 - Vazão x Umidade (Coleta 07 - 9000 BTU/h.

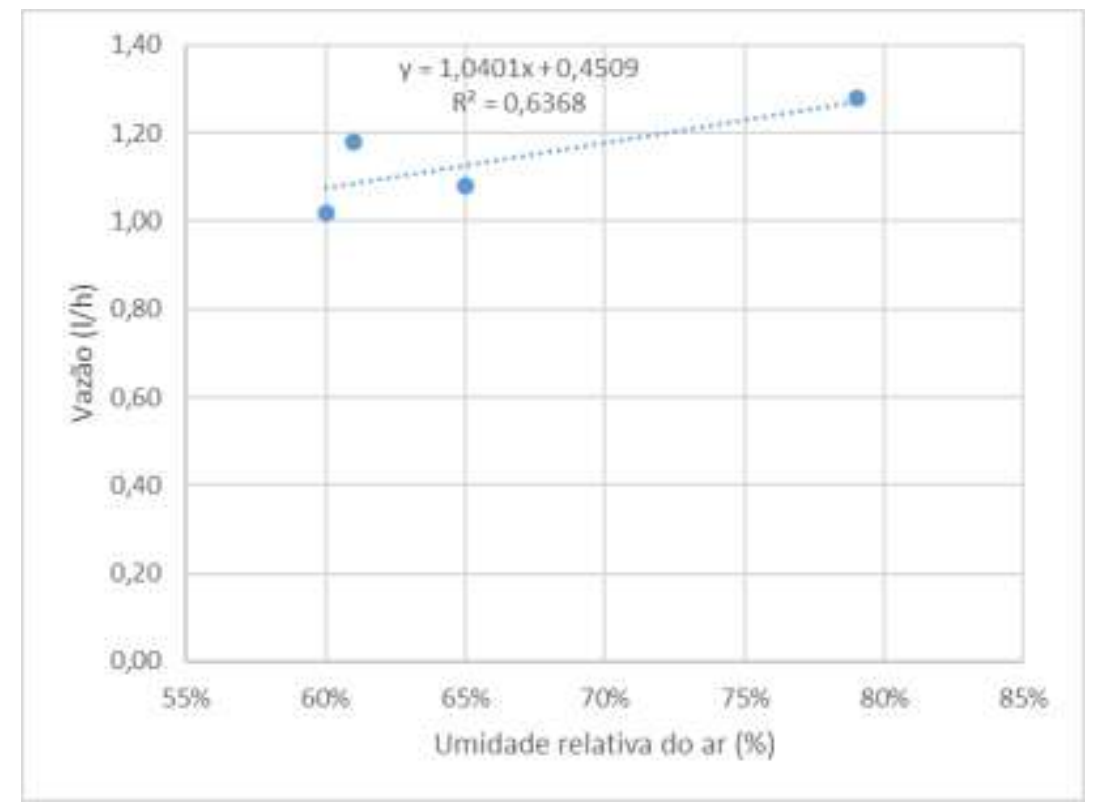

Fonte: Autores (2021).

Assim, é possível observar por meio das figuras anteriores que em cada aparelho de ar condicionado, o aumento dos valores da umidade relativa do ar aponta para um aumento na vazão do efluente gerado por condensação nesses equipamentos.

\subsection{Relação Vazão x Potência}

Foi comparada a vazão obtida com a potência do aparelho condicionador de ar, e com base nelas foram gerados gráficos que ilustram a interação dos respectivos dados. A Figura 7 ilustra o gráfico Vazão X Potência de todos as vazões coletadas e as respectivas potencias dos aparelhos de ar-condicionado.

Figura 7 - Vazão x Potência.

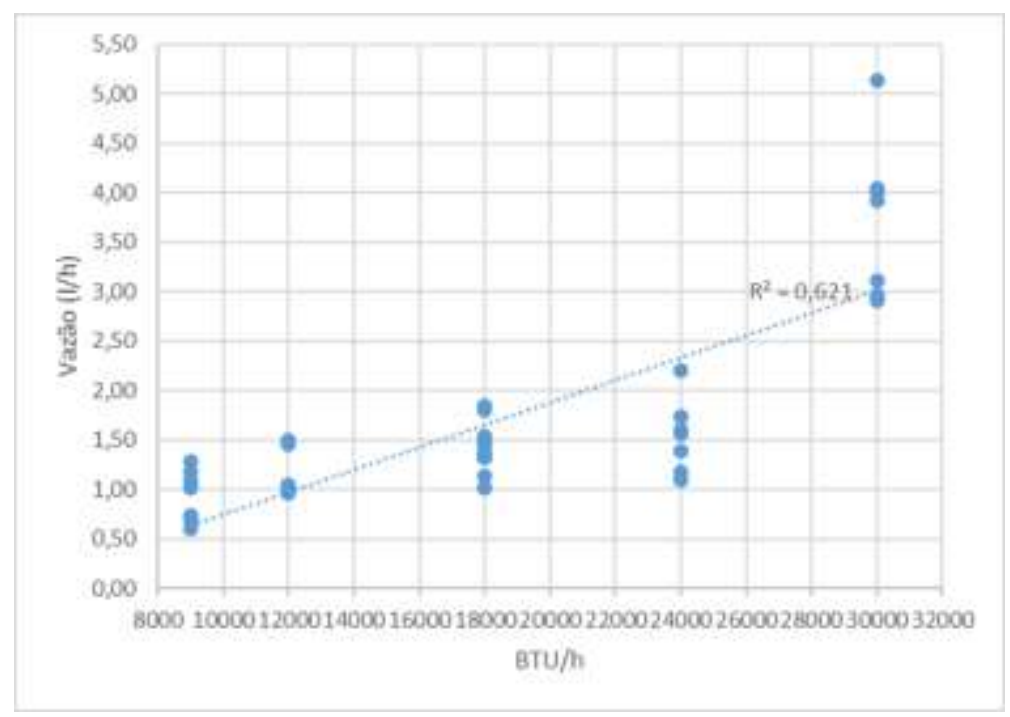

Fonte: Autores (2021).

Pode-se observar por meio da Figura 7, que o aumento dos valores da potência dos aparelhos, em BTU/h, aponta de maneira geral, para um aumento na vazão do efluente gerado por condensação nesses equipamentos 


\subsection{Obtenção da vazão por meio da umidade e BTU/h}

Buscou-se, no presente estudo, obter um modelo que estimasse a vazão da água condensada em condicionadores de ar por meio da umidade e da potência dos aparelhos. Inicialmente todos os dados referentes às grandezas citadas anteriormente, foram organizados em 3 grupos de amostras, os grupos continham dados de vazões horárias, potência em BTU/h e umidade relativa do ar, respectivamente. Posteriormente, foi feita uma regressão linear de múltiplas variáveis, tomando a vazão como variável dependente e a umidade e a potência como variáveis independentes. O processo resultou nos resultados expostos a seguir.

No cenário 1, foram utilizados todos os dados coletados no estudo na regressão. O resultado obtido foi o modelo equacional apresentado a seguir na equação 1 . Sendo Q é a vazão a ser obtida, em litros por hora $(1 / h), H$ é o valor da umidade relativa do ar em porcentagem (\%), e P é a potência do equipamento (BTU/h).

$$
Q=P \cdot 1,130 \cdot 10^{-4}+H \cdot 2,275 \cdot 10^{-2}-1,944 \text { (Equação 01) }
$$

O modelo resultante apresentou um coeficiente de determinação, $R^{2}=0,642$, $\mathrm{O}$ valor absoluto médio do erro do modelo foi de $28,7 \%$. Foi possível gerar o gráfico representado na Figura 8 a partir da equação 1, onde os valores da umidade são fixados e plotados separadamente. De maneira a tornar mais prática a determinação da vazão a partir da potência do aparelho e da umidade do ar.

Figura 8 - Obtenção da vazão - umidades fixas - cenário 1.

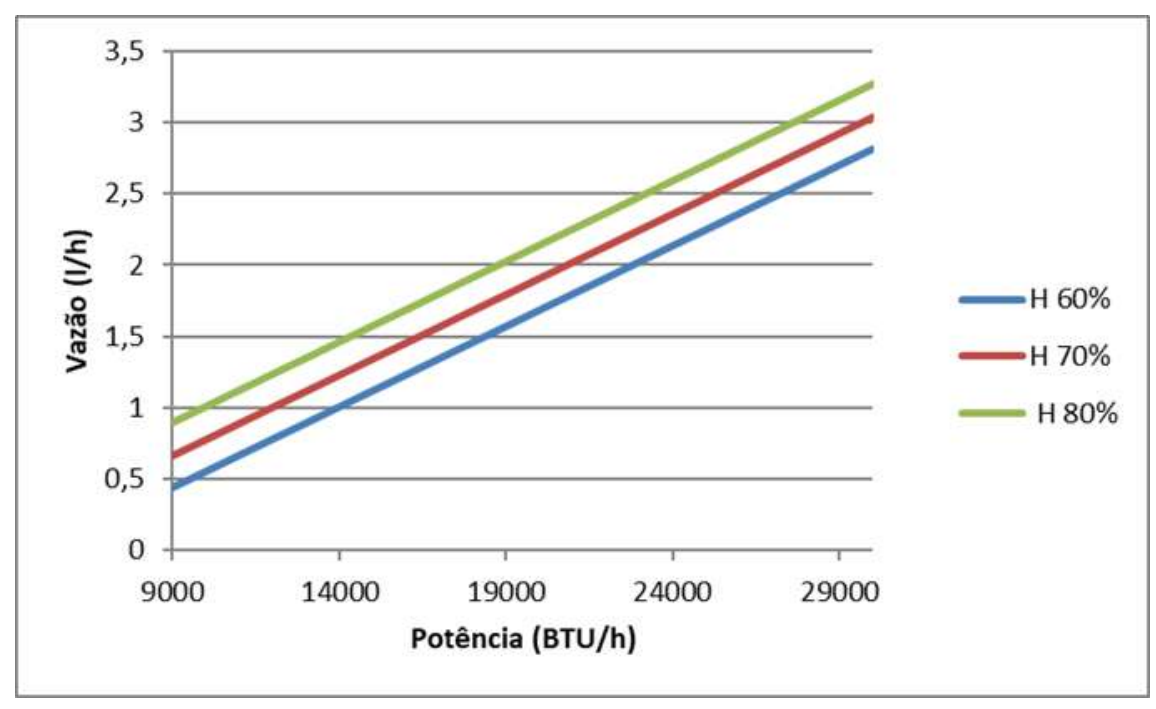

Fonte: Autores (2021).

Objetivando uma análise mais precisa para condicionadores de ar de até 24000 BTUs/h, delineou-se um modelo (cenário 2) desconsiderando-se os condicionadores de ar de $30000 \mathrm{BTUs} / \mathrm{h}$. Tal procedimento decorreu do fato de que os valores de vazão obtidos a partir dos condicionadores de ar de 30000 BTUs/h se distanciavam de uma relação linear, em relação aos outros. Dessa forma, obteve-se o segundo modelo, descrito pela equação 2 . O novo modelo apresentou um coeficiente de determinação, $R^{2}=$ 0,449 e o valor absoluto médio de erro de $17,2 \%$.

$$
Q=P \cdot 4,10 \cdot 10^{-5}+H \cdot 1,25 \cdot 10^{-2}-0,215 \text { (Equação 02) }
$$


A partir da Equação 2, gerou-se o gráfico ilustrado na figura 9, onde os valores da umidade são fixados e plotados separadamente.

Figura 9 - Obtenção da vazão - umidades fixas - cenário 2.

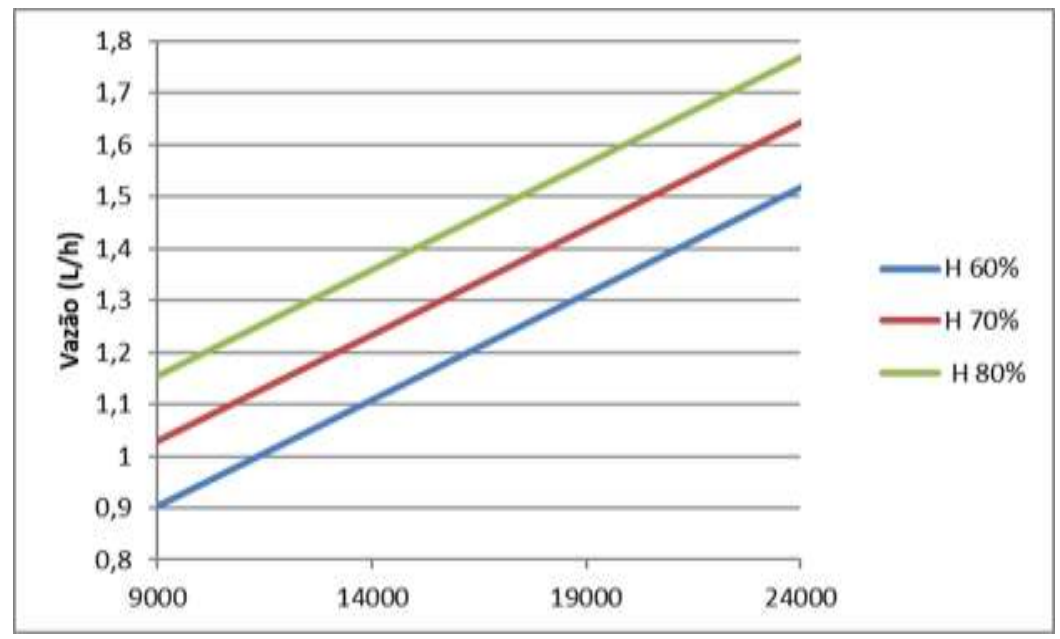

Fonte: Autores (2021).

Para as variações nas relações entre os parâmetros e para o erro encontrado no modelo atribuiu-se, como provável causa, vazamentos na coleta, imprecisão na medição. Bem como, a influência de outros fatores não levados em conta pelo estudo, como a área dos ambientes, vedação térmica, número de pessoas e equipamentos eletrônicos presentes, a idade e a manutenção dos aparelhos. O presente trabalho buscou estimular o uso dessa fonte alternativa de água e contribuir com suas informações para futuros estudos na área.

\section{Conclusão}

De acordo com a análise quantitativa da vazão, baseada nos dados coletados, constatou-se que os parâmetros umidade relativa do ar e potência do equipamento influenciam diretamente na quantidade de efluente gerado.

Obteve-se por meio de regressão linear, uma equação que estima um valor de vazão horária com base em valores fornecidos de umidade relativa do ar e potência do aparelho condicionador de ar. Observou-se que o modelo atendeu, de forma satisfatória, aos objetivos definidos para o trabalho.

Dessa forma, fica evidente o grande potencial de utilização dos efluentes provenientes da condensação em sistemas de climatização, devido à sua considerável vazão e a demanda existente por água, para uso não potável.

Recomenda-se que as futuras pesquisas, além de estimar a vazão da água condensada, procurem comparar os resultados obtidos com os modelos matemáticos encontrados na literatura.

\section{Referências}

ANA (2005). Detalhamento da Gestão da Oferta na Implantação de Programas de Conservação de Água. Conservação e Reuso da água em Edificações. Agência Nacional de Águas (ANA). ANA. https://www.fiesp.com.br/indices-pesquisas-e-publicacoes/conservacao-e-reuso-de-aguas-em-edificacoes-2005/

Arden, S., Morelli, B., Cashman, S., Ma, X., Jahne, M., \& Garland, J. (2021). Onsite Non-potable Reuse for Large Buildings: Environmental and Economic Suitability as a Function of Building Characteristics and Location. Water Research, 191, https://doi.org/10.1016/j.watres.2020.116635

Bastos, C., Túlio, S., \& Franci, R. (2015). Gestão da água em edificações através do aproveitamento de condensação do sistema de ar-condicionado: um exemplo em Vitoria, Brasil. Proceedings of EURO ELECS 2015 - Connecting People and Ideas. Guimarães, Portugal.

Brasil. (2007). Lei N 11.445 de 05 janeiro de 2007. Estabelece diretrizes nacionais para o saneamento básico. http://www.planalto.gov.br/ccivil_03/_ato20072010/2007/lei/111445.htm 
Research, Society and Development, v. 10, n. 13, e104101321100, 2021

(CC BY 4.0) | ISSN 2525-3409 | DOI: http://dx.doi.org/10.33448/rsd-v10i13.21100

Brasil. (1997). Lei No 9.433, de 08 de janeiro de 1997. Institui a Política Nacional de Recursos Hídricos e cria o Sistema Nacional de Gerenciamento de Recursos Hídricos. Brasília, DF. http://www.planalto.gov.br/ccivil_03/leis/L9433.htm

Da Silva, L. C. C., Oliveira Filho, D., Silva, I. R., Pinto A. C. V., \& Vaz, P. N. (2019). Water sustainability potential in a university building - Case study. Sustainable Cities and Society, 47.https://doi.org/10.1016/j.scs.2019.101489

Embrapa. (2018). Clima. Empresa brasileira de pesquisas agropecuárias. (EMBRAPA). https://www.cnpf.embrapa.br/pesquisa/efb/clima.htm

Ercin, A. E., \& Hoekstra, A. Y. (2014). Water footprint scenarios for 2050: A global analysis. Environment International, 64., 71-82. http://dx.doi.org/10.1016/j.envint.2013.11.019

Gil, A. C. (2007). Métodos e técnicas de pesquisa social. (5aed.), Atlas.

Iea. (2018). The future of cooling. International energy agency (IEA).

Inmet. (2018). Instituto Nacional de Meteorologia. http://www.inmet.gov.br

Inmet. (2010). Normais Climatológicas 1981-2010. Instituto Nacional de Meteorologia. Brasília/DF

Mekonnen, M. M., \& Hoekstra, A. Y. (2016). Four billion people facing severe water scarcity. Science. Advances., 2(2) https://www.science.org/doi/10.1126/sciadv.1500323

Paraíba. (2010). Lei № 9.130, de 27 de maio de 2010. Cria o Programa de Conservação e Uso Racional da Água nas Edificações Públicas da Paraíba, conforme especifica e adota outras providências.

Paraíba. (2015). Lei № 10.559, de 18 de novembro de 2015. Dispõe sobre a Instituição da Campanha Permanente de Mobilização Estadual contra o Desperdício de Água no Estado da Paraíba e dá outras providências.

Reichardt, K (2016). Água e sustentabilidade no sistema solo-planta-atmosfera. Manole.

Ren, X., Zhang, Y., \& Chen, H. (2020). Graywater treatment technologies and reuse of reclaimed water for toilet flushing. Environmental Science and Pollution Research, 27, 34653-34663. 10.1007/s11356-019-05154-6

Richardson, R. J. (2017). Pesquisa social:métodos e técnicas. (4a ed.), Atlas.

Siam, L., Al-Khatib, A., Anayah, F., Jodeh, S., Hanbali, G., Khalaf, B., \& Deghles, (2019). A. Developing a Strategy to Recover Condensate Water from Air Conditioners in Palestine. Water, v. 11 (8), 2019. https://doi.org/10.3390/w11081696

Sousa, R. E. B., Rocha, C. M. S., Abreu, F. O. M. S., \& Moraes, S. G. (2016). Caracterização físico-química e microbiológica das águas condensadas de aparelhos de ar-condicionado visando potencial reutilização. Revista Tecnologia, Fortaleza, v. 37 (1), 37-54.

Tayara, A., Shanableh, A., Atieh, M. A., Abdallah, M., Battacharjee, S., Mustafa, A., \& Bardan, M. A. (2021). Feasibility and impact of greywater recycling in four types of buildings in Sharjah, United Arab Emirates. IOP Conf. Series: Earth and Environmental Science, 75. 10.1088/1755-1315/725/1/012009. 